\section{Should Hospital Pharmacies That Are Not Fully Compliant with USP General Chapter $<797>$ Standards Outsource, to the Fullest Extent Possible, the Preparation of Compounded Sterile Products to a Facility That Is Compliant?}

\section{THE "PRO" SIDE}

Compounding has been defined as "the combining, mixing, or altering of ingredients to create a customized medication for an individual patient in response to a licensed practitioner's prescription."1 Compounding is intended to be patient-specific and small-scale in nature. It is not intended as an alternative to the purchase of commercially available pharmaceutical products, which must be manufactured according to the rigorous requirements laid out in the federal government's Good Manufacturing Practices. ${ }^{2}$ Those requirements include end-stage sterilization, testing for both sterility and medicinal contents, and many other types of testing that are typically not carried out in hospital pharmacies. Although it is well accepted that compounding plays an important role in the provision of medications or medication dosage forms that are not commercially available, there are significant risks associated with the compounding of pharmaceutical products. ${ }^{3,4}$ What can be done to minimize those risks?

Compounding of sterile products in a hospital pharmacy department should occur only when 2 conditions are met: first, a commercially manufactured alternative is not available and second, the hospital pharmacy department's sterile compounding services are, at a minimum, fully compliant with General Chapter $<797>$ standards. $^{5}$

With respect to the first condition, hospitals that insist on compounding products that are commercially available in the same strength and format must consider the hidden costs of the risks to which they are exposing their patients and their organizations. In these cases, the production of compounded products should be "outsourced" to the pharmaceutical industry; in other words, the products should be purchased rather than being prepared in the hospital. The purchase of commercially manufactured products should also be considered when alternatives are available that are not identical but are essentially interchangeable with the prescribed product. The risks associated with unnecessary compounding of a product, relative to the risks of using a very similar commercially manufactured product, need to be carefully weighed.

With respect to the second condition, General Chapter $<797>$ standards are perceived by some hospitals as being overly rigorous. However, the authors of a recent review noted that even in a pharmacy that is fully compliant with General Chapter <797> standards, the sterility assurance level is several orders of magnitude below that of products manufactured under GMP standards. ${ }^{3}$ How much lower are we prepared to go if we don't accept the need for General Chapter <797> compliance? As the Institute for Safe Medication Practices (US) wrote in its review of an incident involving contaminated total parenteral nutrition bags that claimed the lives of 9 patients, "partial compliance will not even partially protect patients from the risk of infection from contaminated [compounded sterile preparations]"' (emphasis in the original).

Unfortunately, a number of studies in the Canadian hospital pharmacy practice setting have shown that compliance with standards for sterile compounding is far from ideal. ${ }^{7-10}$ A 1992 study of compliance with the sterile compounding standards in place at that time ${ }^{8}$ and a similar survey conducted in $2007^{9,10}$ both revealed concerning rates of noncompliance with existing standards. Deficiencies in sterile compounding practices have led to tragic outcomes. In the United States, an outbreak of fungal meningitis in 2012 was traced back to contaminated methylprednisolone products prepared by the New England Compounding Center (NECC). ${ }^{11}$ Roughly 14000 patients received injections of the contaminated product. Since that time, the death toll has risen to 64 patients, and thousands more are suffering serious morbidity as a result of having received the contaminated product. Unfortunately, the NECC tragedy is just one of many failures in sterile compounding that have had tragic consequences for patients. ${ }^{4}$

Returning to the question of what should be done to minimize the possibility of an event like the NECC tragedy occurring in a Canadian hospital pharmacy, we must remember that after outsourcing commercially available products to the pharmaceutical industry, the next high-priority initiative should be the consolidation of production of compounded sterile products in facilities that are fully compliant with General Chapter $<797>$ requirements. Compliant facilities might be other hospitals or private sterile compounding enterprises that can demonstrate full compliance with General Chapter <797> standards. Health regions should explore the option of consolidating production in 
one or more of their facilities that have achieved full compliance with the standards. However, hospitals should not rule out the possibility of using private, for-profit facilities if those entities can demonstrate current compliance with the standards and an uncompromising approach to the safety and quality of their products.

In a recent conversation, the $\mathrm{CEO}$ of the Canadian division of a large multinational company that operates compounding centres in Canada quoted the company's president as stating that sterile compounding carries the highest risk of any of the company's business units and that USP General Chapter <797> is simply not good enough for the company. That is the type of commitment to quality that is needed, regardless of whether the provider is in the public or the private sector. The capital and operating costs associated with upgrading compounding facilities in every Canadian hospital are likely to be prohibitive. As such, the creation of regionalized compounding centres, each serving a relatively large number of hospitals, is likely the best approach to achieving high-quality sterile compounding for hospitals across Canada. If a particular hospital's pharmacy department cannot meet and maintain the General Chapter $<797>$ standards for sterile compounding, every effort should be made to obtain such products from a provider that can.

\section{References}

1. Report: Limited FDA survey of compounded drug products. Silver Spring (MD): Food and Drug Administration (US); 2009 Jun 18 [cited 2014 Nov 27]. Available from: www.fda.gov/Drugs/GuidanceComplianceRegulatory Information/PharmacyCompounding/ucm 155725.htm

2. Good manufacturing practices. Ottawa $(\mathrm{ON})$ : Health Canada; modified 2014 Jul 22 [cited 2014 Nov 19]. Available from: www.hc-sc.gc.ca/ dhp-mps/compli-conform/gmp-bpf/index-eng.php

3. Gudeman J, Jozwiakoeski M, Chollet J, Randell M. Potential risks of pharmacy compounding. Drugs R D. 2013;13(1):1-8.

4. Staes C, Jacobs J, Mayer J, Allen J. Description of outbreaks of health-careassociated infections related to compounding pharmacies, 2000-2012. Am J Health Syst Pharm. 2013;70(15):1301-12.

5. General chapter $<797>$ pharmaceutical compounding — sterile preparations. In: United States Pharmacopeia-National Formulary (USP-NF). Rockville (MD): US Pharmacopeial Convention; updated periodically.

6. TPN-related deaths call for FDA guidance and pharmacy board oversight of USP chapter<797>. Acute Care ISMP Saf Alert. 2011 Apr 7 [cited 2014 Nov 19]. Available from: https:/www.ismp.org/newsletters/acutecare/ articles/20110407.asp

7. Douglass K, Kastango ES. The 2012 USP < 797> compliance survey: measuring progress. Pharm Purch Prod. 2012;9(10):4.

8. Fitch DP, Hall KW. Survey of sterile product compounding practices in Canadian hospital pharmacies. Can J Hosp Pharm. 1993;46(6):249-60.

9. Warner T, Nishi,C, Checkowski R, Hall KW. Survey of sterile admixture practices in Canadian hospital pharmacies: Part 1. Methods and results. Can J Hosp Pharm. 2009;62(2):100-11.

10. Warner T, Nishi,C, Checkowski R, Hall KW. Survey of sterile admixture practices in Canadian hospital pharmacies: Part 2. More results and discussion. Can J Hosp Pharm. 2009;62(3):192-203.

11. US Congress, House of Representatives, Committee on Energy and Commerce. FDA's oversight of NECC and Ameridose: a history of missed opportunities? Preliminary Majority Staff Report. 113th Congress, $2013 \mathrm{Apr}$ 16 [cited 2014 Nov 19]. 43 p. Available from: http://docs.house.gov/ meetings/IF/IF02/20130416/100668/HHRG-113-IF02-20130416-SD101.pdf
Kevin W Hall, BSCPharm, PharmD, FCSHP

Clinical Associate Professor

Faculty of Pharmacy and Pharmaceutical Sciences

University of Alberta

Edmonton, Alberta

Kevin Hall is also an Associate Editor with the CJHP.

Competing interests: Kevin Hall has received honoraria from Pharmaceutical Partners of Canada (a unit of the Fresenius Kabi Group, which provides sterile compounding services) for moderating and participating in a luncheon panel discussion at the 2013 Banff Seminar regarding the vision for pharmacy practice in the near future and for a presentation at the 2014 Banff Seminar dealing with sterile compounding and the oncology underdosing error.

\section{THE “CON" SIDE}

Most hospital pharmacies and some community pharmacies compound sterile products to address patient needs that cannot be met with commercially available preparations. Sterile compounding falls within the scope of practice of pharmacists, is provincially regulated, and is a long-standing and well-established component of pharmacy services in most hospitals. If this service were not available in a hospital, certain patients would not get the care they require, and overall patient care would suffer.

Although it would be ideal to have all compounded sterile products prepared under the rigorous Good Manufacturing Practice (GMP) standards ${ }^{1}$ that apply to pharmaceutical manufacturers, it is recognized that compliance with GMP standards would be prohibitively expensive and impossible for most hospitals to achieve. In the United States, the US Pharmacopeial Convention has established guidelines for the compounding of sterile product preparations, known as USP General Chapter $<797>$. ${ }^{2}$ The risk associated with products prepared under General Chapter $<797>$ standards is greater than for products prepared under GMP standards, but adherence with the General Chapter $<797>$ guidelines ensures a high standard of safety and quality for compounded parenteral products. It is important to understand that the General Chapter $<797>$ standards represent a compromise between the desire to meet patients' needs for compounded medications and the desire to have zero defects in the production of sterile products. In the absence of such a compromise, the GMP standards would be required in all settings. Neither the Canadian federal government nor any provincial government in Canada has made compliance with General Chapter < 797> a requirement for sterile compounding in their respective jurisdictions. The General Chapter < 797> guidelines are an excellent set of standards and something to strive for, but they are not a requirement in Canada. 
If only pharmacies fully compliant with General Chapter $<797>$ were permitted to prepare compounded sterile products, few hospital pharmacies would be able to provide sterile compounding services. This situation would have negative implications for patient care, particularly in rural areas where the likelihood of having a fully compliant pharmacy nearby is typically very low. It would also undoubtedly result in major cost increases for hospitals, at a time when staying within budget is already a challenge. Where would budget cuts be made in order to implement improved standards that are not required in Canada? Many hospitals realize substantial savings by preparing medications in house rather than buying commercially available versions. An example would be the batch preparation of minibags containing a standard dose of a frequently used antibiotic, with the bags being stored appropriately and used over a short period of time.

Outsourcing has been promoted as a solution for hospitals that are dealing with the issue of how to manage the preparation of compounded sterile products. However, there is no evidence that having others provide the service is likely to generate better outcomes than the current practice of preparing compounded sterile products in house. In fact, most of the problems with compounded sterile products that have become public, such as microbial or fungal contamination ${ }^{3-5}$ and dosing errors ${ }^{6}$ have occurred in large, private sector compounding pharmacies, rather than in hospitals. In addition, it is worth noting that the report on the oncology dosing issues that occurred in a contracted compounding pharmacy in Ontario ${ }^{6}$ criticized the hospitals for not providing detailed instructions on how to prepare the products. If a hospital that outsources its preparation of compounded sterile products remains responsible for managing and overseeing the operational aspects of the service, what are the operational advantages of outsourcing?

In summary, there is little justification for making major changes to the way that hospital pharmacies manage the preparation of compounded sterile products. One potentially worthwhile change would be the implementation of an annual report of General Chapter $<797>$ compliance by each hospital. Such a reporting requirement would encourage hospitals to improve their compliance with these particular standards, would encourage governments to consider an appropriate standard, and would encourage hospitals to meet the Guidelines for SAFE Preparation of Sterile Compounds, as presented by the Institute for Safe Medication Practices (US). ${ }^{7}$

\section{References}

1. Good manufacturing practices. Ottawa (ON): Health Canada; modified 2014 Jul 22 [cited 2014 Nov 19]. Available from: www.hc-sc.gc.ca/dhp-mps/ compli-conform/gmp-bpf/index-eng.php

2. General chapter $<797>$ pharmaceutical compounding-sterile preparations. In: United States Pharmacopeia-National Formulary (USP-NF). Rockville (MD): US Pharmacopeial Convention; updated periodically.

3. Gudeman J, Jozwiakoeski M, Chollet J, Randell M. Potential risks of pharmacy compounding. Drugs R D. 2013;13(1):1-8.

4. Staes C, Jacobs J, Mayer J, Allen J. Description of outbreaks of healthcare-associated infections related to compounding pharmacies, 2000-2012. Am J Health Syst Pharm. 2013;70(15):1301-12.

5. US Congress, House of Representatives, Committee on Energy and Commerce. FDA's oversight of NECC and Ameridose: a history of missed opportunities? Preliminary Majority Staff Report. 113th Congress, 2013 Apr 16 [cited 2014 Nov 19]. 43 p. Available from: http://docs.house.gov/meetings/IF/IF02/ 20130416/100668/HHRG-113-IF02-20130416-SD101.pdf

6. Thiessen J. A review of the oncology under-dosing incident. A report to the Ontario Minister of Health and Long-Term Care. Toronto (ON): Ministry of Health and Long-Term Care; 2013 Jul 12 [cited 2014 Aug 30]. Available from: www.health.gov.on.ca/en/public/programs/cancer/drugsupply/docs/ report_thiessen_oncology_under-dosing.pdf

7. Proceedings from the ISMP Sterile Preparation Compounding Safety Summit: Guidelines for SAFE preparation of sterile compounds. Horsham (PA): Institute for Safe Medication Practices; 2013 [cited 2014 Aug 30]. Available from: www.ismp.org/tools/guidelines/IVSummit/IVCGuidelines.pdf

Ron McKerrow, BScPharm, MBA

Concilio Consulting Inc

Delta, British Columbia

Competing interests: None declared. 